\title{
Relationship of the Mean Glandular Dose with Compressed Breast Thickness in Digital Mammography
}

\author{
Khadka $S^{1}$, Jha $A^{1}$, Chaudhary $R^{2}{ }^{2}$, Shrestha $S^{1}$ \\ ${ }^{1}$ Department of Radiology, TU Teaching Hospital, Maharajgunj, Kathmandu, Nepal \\ ${ }^{2}$ Department of Radiology, University of Texas Medical Branch, Galveston, Texas, USA
}

Received: February 20, 2020

Accepted: May 30, 2020

Published: June 30, 2020

Cite this paper:

Khadka S, Jha A, Chaudhary RK, Shrestha SL. Relationship of the Mean Glandular Dose with Compressed Breast Thickness in Digital Mammography. Nepalese Journal of Radiology 2020;10(15):11-15. http://dx.doi. org/10.3126/njr.v10i1.28539

\section{ABSTRACT}

Introduction: Mammography is one of the most commonly performed radiological investigations for evaluation of breast cancer. As it involves ionizing radiation, there remains a risk of radiation induced cancer. In this study, we evaluated compressed breast thickness (CBT) and mean glandular dose (MGD) during routine mammography.

Methods: This prospective study was performed in the Department of Radiology and Imaging of TUTH. Data of 500 consecutive patients who underwent mammography over a period of 4 months (June 2018 to September 2018) was collected. The age, CBT and MGD were recorded. Pearson correlation and paired-t tests were performed.

Results: Most of the patients belonged to 41-50 years age group. MGD was significantly higher in patients with increased CBT. The CBT and MGD was higher in MLO view compared to CC views. The mean value of total MGD for four views was 5.1 $\pm 1.4 \mathrm{mGy}$. There was significant positive correlation ( $r=0.517$ ) between CBT and MGD with increase in MGD with increase in CBT.

Conclusions: The MGD and dose equivalent in our routine mammography is within the recommended limits. MGD increases with increasing CBT and vice-versa. Hence, decreasing the thickness of compressed breast, can decrease the amount of radiation absorbed by the glandular tissue of the breast.

Key words: Compressed Breast Thickness, Mammogram, Mean Glandular Dose

\section{INTRODUCTION}

Mammography remains an important screening and diagnostic tool for evaluation of breast lesions and is often the first investigation of choice for evaluation of breast cancers. ${ }^{1,2}$ Current guidelines from the U.S.

Correspondence to: Dr. Anamika Jha, MD

Department of Radiology Preventive Services Task Force recommends screening mammography once in two years

TU Teaching Hospital, Maharajgunj

Kathmandu, Nepal

Email: dranamikakasyap@gmail.com for women aged 50-74 years. ${ }^{3}$ On the contrary, medium, provided the original work is properly cited 
the American Medical Association and the American College of Radiology (ACR) recommends annual screening from the age of 40 years. ${ }^{4}$ Screening mammogram leads to early detection of breast cancers, when they are most curable and breast-conservation therapies are available. ${ }^{5}$

Visualization of micro calcification or early non-palpable masses within the normal breast soft tissue requires breast radiography of highest quality. The glandular tissue is radiosensitive with tissue weighting factor of 0.12 and like all other radiological investigations using $\mathrm{X}$-ray, it also has a small stochastic risk of inducing cancer. Hence, it is important to evaluate the risk from the dose delivered to the patient during the imaging process. ${ }^{2,6}$ The life time attributable risk of annual mammography starting at age of 40 years is 1.3 to 1.7 fatal cancer cases per 100,000 women. ${ }^{7}$ Optimum imaging techniques are needed for a balance between high quality images and radiation exposure to avoid increasing risk of radiation elated cancer while obtaining diagnosis. It is also necessary to evaluate the dose delivered to the breast to minimize the risk of radiation induced cancer. Absorbed dose is the radiation energy deposited per unit mass of tissue, expressed as milligray (mGy). As the fibroglandular tissue is the radiosensitive part, absorbed dose in breast is referred to as the mean glandular dose (MGD). ${ }^{8}$ These are the recommended measures of radiation risk quantification for mammography. ${ }^{1}$ In this study, we evaluated the compressed breast thickness (CBT) and absorbed dose in our patients during mammography.

\section{METHODS}

This prospective study was performed in the Department of Radiology and Imaging of Tribhuvan University Teaching Hospital. Data of 500 consecutive patients without prior history of mastectomy who underwent mammography over a period of 4 months (June 2018 to September 2018) were collected. The two basic projections, craniocaudal (CC) and mediolateral oblique (MLO) views were done for all subjects with the mammographic unit (MAMMOMAT Fusion) using workstation of Syngovia software. Detailed information which included patient's age, CBT and MGD of CC and MLO of each view was recorded in a predesigned data collection sheet. The CBT and MGD were calculated by the machine itself and displayed on the monitor.

MGD is measured in this machine based on the formula, MGD $=\mathrm{K} x$ g $x$ c $x \quad \mathrm{~s}$, where $\mathrm{K}$ is the entrance surface air kerma (without backscatter), $\mathrm{g}$ corresponds to a glandularity of $50 \%, \mathrm{c}$ is correction factor for the difference in composition of typical breasts from $50 \%$ glandularity and the factor $\mathrm{s}$ corrects for differences due to the choice of $\mathrm{X}$-ray spectrum.

Data were presented as mean and standard deviation for all variables. Statistical analyses were carried out with the help of SPSS version 20. The mean, standard deviation (SD) were calculated. Pearson correlation test and paired t-test were performed.

\section{RESULTS}

The sample consisted of 500 female patients, most in the 41-50 years age group (Figure 1). The CBT was highest in 31-40 age group in the $\mathrm{CC}$ view and in 41-50 age group in the MLO view (Figure 2).

CBT ranged from a minimum of $18 \mathrm{~mm}$ in the RCC and maximum of $96 \mathrm{~mm}$ in LMLO positions. The mean and SD of CBT for CC and MLO views for both breasts were $50.73 \pm 11.11$ $\mathrm{mm}$ and $59.14 \pm 13.52 \mathrm{~mm}$, respectively and that in each view as mentioned in table 1 . There was significant difference in means of CBT between CC and MLO views.

The mean and SD of MGD for CC and MLO views were $1.21 \pm 0.35 \mathrm{mGy}$ and $1.34 \pm 0.37$ mGy respectively with significant difference between CC and MLO views, being more in the MLO view. The mean MGD for each view is shown in the table 1. MGD increased with increasing CBT in all the views, as shown in the figure 3 .

The mean value of total MGD for four views

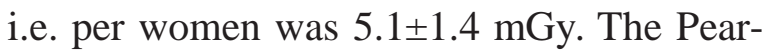
son's correlation coefficient between the CBT 
and MGD for all four views combined was 0.517 and p-value was less than 0.01 suggesting higher MGD with increase in CBT.

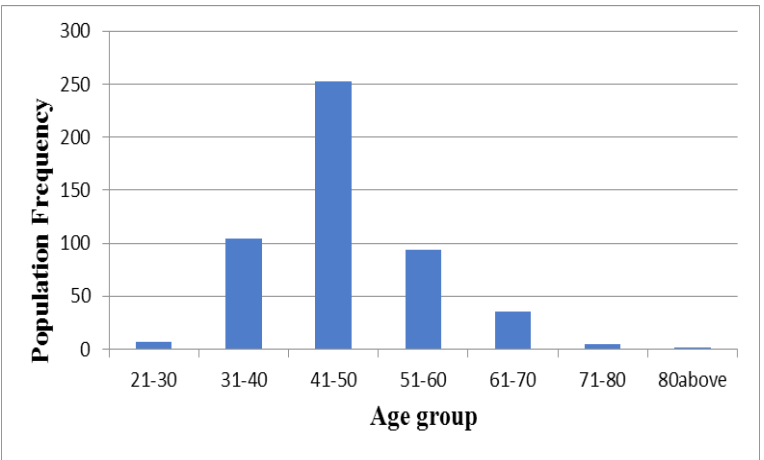

Figure 1: Bar chart of distribution of sample size according to age group.

Variation of CBT in CC and MLO views in various age groups

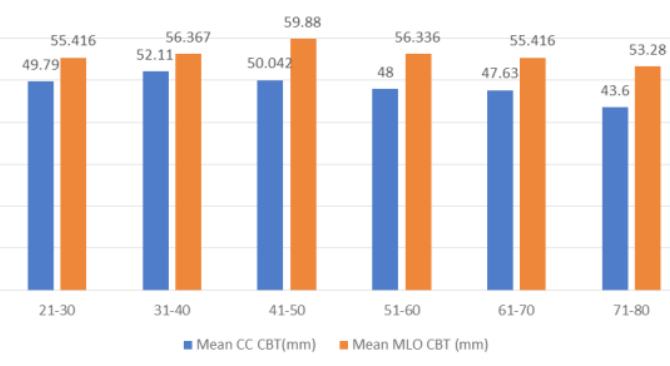

Figure 2: Mean $C B T$ in $C C$ and $M L O$ views with age.

Table 1: Mean and SD of MGD and CBT of right $C C(R C C)$, left $C C(L C C)$, right $M L O$ (RMLO) and left MLO (LMLO.

\begin{tabular}{|l|l|l|l|l|}
\multirow{2}{*}{ Variables } & \multicolumn{2}{|c|}{ MGD } & \multicolumn{2}{c|}{ CBT } \\
\cline { 2 - 5 } & $\begin{array}{l}\text { Mean } \\
(\mathrm{mGy})\end{array}$ & SD & $\begin{array}{r}\text { Mean } \\
(\mathrm{mm})\end{array}$ & SD \\
\hline RCC & 1.22 & 0.38 & 51.17 & 11.61 \\
\hline LCC & 1.20 & 0.37 & 50.29 & 11.34 \\
\hline RMLO & 1.36 & 0.40 & 59.76 & 13.77 \\
\hline LMLO & 1.32 & 0.38 & 58.52 & 13.90 \\
\hline
\end{tabular}
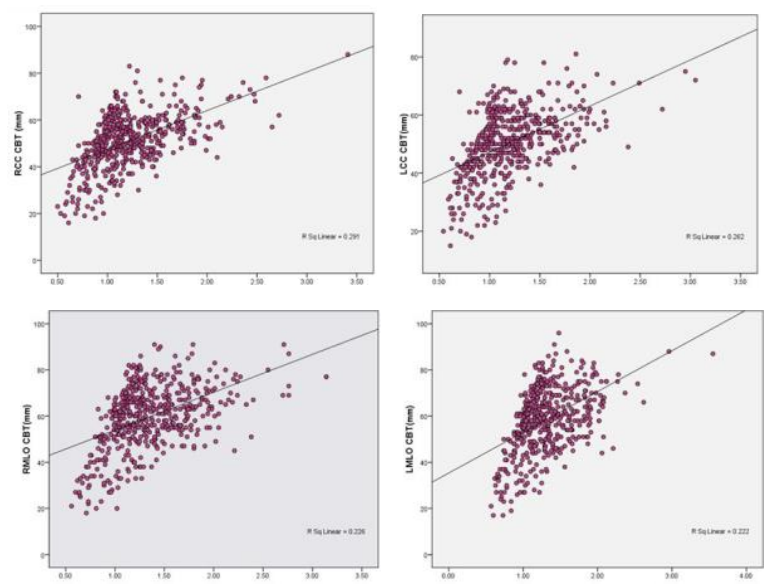

Figure 3: Scatter Plot diagram of CBT and $M G D$ in RCC, LCC, RMLO and LMLO views.

\section{DISCUSSION}

ACR recommends MGD of less than 3.0 mGy per view. ${ }^{9}$ Two-view digital mammography and screen-film mammography involve average mean glandular radiation doses of 3.7 and $4.7 \mathrm{mGy}$, respectively. (7) The mean MGD for each CC and MLO views were 1.21 $\mathrm{mGy}$ and $1.34 \mathrm{mGy}$, respectively, and that per mammogram was $5.1 \pm 1.4 \mathrm{mGy}$ which was well within the recommended limits by ACR. Increase in MGD with CBT as in our study, has been documented in multiple other studies. ${ }^{7,10,11}$

MGD is the exposure to a particular region of the body and depends upon $\mathrm{kVp}$ of the $\mathrm{x}$ ray tube; target/filter combination, breast composition and breast thickness. In breast, the fibroglandular tissue is most radiosensitive and this itself may predispose to breast cancer. Radiation weighting factor for breast tissue is one. The current ICRP tissue-weighting factor for breast tissue is 0.12 in 2007, previously being 0.15 in 1977 to 0.05 in $1991 .^{6,12,13}$

In our study, we found that MGD was significantly higher in MLO view compared to CC projection unlike study done by Xiang et al. ${ }^{14}$, where there was no significant difference in MGD between CC and MLO views. Other studies have also observed a trend for higher MGD in MLO view compared to CC view. ${ }^{14}$ This can be attributed to greater inclusion of pectoral muscle which has higher attenuation and hence higher radiation dose. ${ }^{1,9,15}$ CBT was 
significantly higher in MLO view compared to $\mathrm{CC}$ view in our studies comparing well to others including study by Xiang et al. This can also be explained by the inclusion of denser pectoral muscle. ${ }^{14}$

\section{CONCLUSION}

Complying with ACR guidelines for MGD is important to reduce risk of radiation induced cancer in patients. The radiation exposure in our patients per mammogram is within the recommended limits. MGD shows a proportionate variation with the CBT and so, decreasing the thickness of breast by uniform compression, can decrease the amount of radiation absorbed by the glandular tissue of the breast.

\section{CONFLICT OF INTEREST}

None

\section{SOURCES OF FUNDING}

None

\section{REFERENCES}

1. Hussain M, Hashim O, Abdullattief S. Estimation Radiation Risk during Mammography in Sudan. Asian $J$ Med Cli Sci 2012;1:56-60. Available from: https://www.researchgate.net/ publication/234746425_Estimation radiation_risk_during_mammography in_Sudan [Accessed 15th March 2020].

2. Sickles EA, Filly RA, Callen PW. Breast cancer detection with sonography and mammography: comparison using stateof-the-art equipment. AJR Am. J. Roentgenol 1983;140(5):843-5. https:// doi.org/10.2214/ajr.140.5.843

3. Frankl G. The use of screening mammography.

Cancer 1987;60(S8):1979-83. https://

doi.org/10.1002/1097 0142(19901015)60:8+\%3C1979::AIDCNCR2820601509\%3E3.0.CO;2-T

4. Monticciolo DL, Newell MS, Moy L,
Niell B, Monsees B, Sickles EA. Breast Cancer Screening in Women at HigherThan-Average Risk: Recommendations From the ACR. J. Am. Coll. Radiol 2018;15(3):408-14. $\quad$ https://doi. org/10.1016/j.jacr.2017.11.034

5. Tabar L, Dean P. The control of breast cancer through mammography screening. What is the evidence?. Radiol Clin North Am 1987;25(5):993-1005. Available from: https://europepmc.org/ article/med/3306777 [Accessed 18th March 2020].

6. Dance D, Skinner C, Carlsson GA. Breast dosimetry. Applied Radiation and isotopes 1999;50(1):185-203. https:// doi.org/10.1016/S0969-8043(98)00047$\underline{5}$

7. Hendrick RE. Radiation doses and cancer risks from breast imaging studies. Radiology 2010;257(1):246-53. https:// doi.org/10.1148/radiol.10100570

8. Hruska CB, O'Connor MK. Curies, and Grays, and Sieverts, Oh My: A Guide for Discussing Radiation Dose and Risk of Molecular Breast Imaging. J Am Coll Radiol 2015;12(10):1103-5. https://doi. org/10.1016/j.jacr.2015.07.001

9. Sookpeng S, Ketted P. Mean glandular dose from routine mammography. Naresuan University Journal: Science and Technology (NUJST) 2013;14(3):19-26. Available from: file:///C:/U sers/Radiolog y.mth/ Downloads/188--373-1-10-20130731. pdf [Accessed 21st March 2020].

10. Bor D, Tukel S, Olgar T, Toklu T, Aydın E, Akyol O. Investigation of mean glandular dose versus compressed breast thickness relationship for mammography. Radiat Prot Dosimetry 2008;129(1-3):160-4. https://doi.org/10.1093/rpd/ncn140

11. Pwamang CK. Assessment of Mean Glandular Dose to Patients from Digital Mammography Systems: University of Ghana; 2016. Available from: https:// 
inis.iaea.org/search/searchsinglerecord. aspx? recordsFor $=$ SingleRecord \&

$\underline{\mathrm{RN}=47108670}$ [Accessed 23rd March 2020].

12. Hendrick RE, Pisano ED, Averbukh A et al. Comparison of Acquisition Parameters and Breast Dose in Digital Mammography and Screen-Film Mammography in the American College of Radiology Imaging Network Digital Mammographic Imaging Screening Trial. AJRAm. J. Roentgenol 2010;194(2):3629. https://doi.org/10.2214/AJR.08.2114

13. Valentin J. International Commission on Radiological Protection. The 2007 recommendations of the international commission on radiological protection. Annals of the ICRP, ICRP Publication 2007;103:2-4.

14. Xiang D, Jin W, Yang CY et al. Investigation of mean glandular dose in diagnostic mammography in China. Biomed. Environ. Sci. 2014;27(5):396-9. https://doi.org/10.3967/bes2014.067

15. Kunosic S, Ceke D, Kopric M, Lincender L. Determination of mean glandular dose from routine mammography for two age groups of patients. HealthMED 2010;4(1):125-31. Available from: https://www.researchgate.net/publicatio n/258121405_Determination_of_mean glandular_dose from routine mammog raphy_for_two_age_groups_of_patients [Accessed 19th March 2020]. 